\title{
Long-term follow up of patients treated with a software based antitachycardia pacemaker
}

\author{
Derek T Connelly, Mark A de Belder, David Cunningham, Alberto N Lopes, \\ Anthony F Rickards, Edward Rowland
}

\begin{abstract}
Introduction-Over the past decade, several advances have been made in the management of tachycardias by pacing techniques, but limited data are available on the long-term outcome of patients treated with antitachycardia pacemakers.

Patients and methods-An antitachycardia pacemaker, the Intermedics Intertach, was implanted in 22 (17 female) patients with supraventricular tachycardia over a five year period. All were selected after detailed evaluation and testing of a temporary antitachycardia pacemaker system showed that their arrhythmia could be stopped promptly, reliably, and under different physiological conditions.

Results-The 22 patients have been
\end{abstract} followed up for a mean period of 57.3 (range 19-76) months. All except one of the patients has had frequent episodes of tachycardia reliably ended by the pacemaker. Complications have occurred in seven patients, necessitating removal of the pacing system in four. Of the 18 patients who continue to have pacemakers, seven are being treated with $\beta$ blockers or verapamil; no other antiarrhythmic drugs are being taken.

Conclusions-Antitachycardia pacing is an acceptable long-term option for carefully selected patients with supraventricular tachycardia, but even after extensive testing a substantial number of the patients may continue to require drug treatment. Furthermore, the widespread use of curative techniques for supraventricular arrhythmias (catheter ablation and surgery) has decreased the need for this palliative treatment.

\section{(Br Heart f 1993;69:250-254)}

Royal Brompton National Heart and Lung Hospital, London $M$ A de Belder D Cunningham A N Lopes A F Rickards E Rowland Correspondence to Dr Derek T Connelly,
Royal Brompton Nationa Royal Brompton National Heart and Lung Hospital, Sydney Street

Accepted for publication 8 September 1992
The finding that a characteristic of reentrant tachycardia is its ability to be terminated by premature stimuli has been used to develop permanent antitachycardia pacemakers. ${ }^{12}$ The earliest units were patient activated, asynchronous, ineffective, and bulky. Early automatic units were only effective for a proportion of cases because only single stimuli were delivered, but subsequent units with modes capable of delivering one or two stimuli with automatic scanning of electrical diastole were found to be considerably more effective ${ }^{3}$ Further developments have been the introduction of burst pacing modes capable of delivering several stimuli at a rapid rate. ${ }^{4}$
A major limitation of automatic units arises from the difficulty in discriminating between paroxysmal tachycardia and sinus tachycardia. Until recently discrimination has only $\stackrel{\triangleright}{\varrho}$ been on a rate criterion, which has been $\tilde{\omega}^{2}$ acceptable when tachycardia is particularly $\overrightarrow{0}$ rapid or sinus tachycardia limited. Recently additional discrimination has been by use of $\vec{\omega}$ rate of change criteria at the onset of tachycardia. A disadvantage of this mode is the failure to recognise tachycardia when the onset is more gradual.

The development of software programming $O$ capabilities has profoundly increased the number of options available for detection and termination of tachycardia. The Intertach 262-12 (Intermedics Inc, Angleton, Texas, USA) incorporates $2 \mathrm{k}$ bytes of software accessible memory, reached through an exter- $\bullet$ nal programmer, in a bipolar SSI pacemaker. Nine programmable algorithms are available for detection of tachycardia, each incorporating up to four variables (rate, sudden onset, rate stability, sustained high rate); independent primary and secondary response programs are available to terminate tachycardia and each has a wide variety of programmable options. These comprehensive detection algorithms and treatment modes will only be of clinical value if the antitachycardia function $\mathbb{D}$ results in reliable and prompt termination of tachycardia under all physiological conditions.

We describe the clinical and electrophysiological characteristics of 22 consecutive patients, of whom 21 had the Intertach 26212 implanted, and one was given its succes- $\frac{T}{2}$ sor, the Intertach II 262-16. In each case the patients were selected after detailed testing o with an external antitachycardia pacemaker.

\section{Patients and methods}

Between February 1985 and December 1989, twenty two antitachycardia pacemakers were? implanted at the National Heart and ${ }_{0}$ Brompton Hospitals, London, in patients $\frac{\vec{D}}{\mathrm{D}}$ with supraventricular tachycardia. The mean $\stackrel{?}{\mathbb{D}}$ age of the patients was 41.2 years (range $\varrho$ 16-78), and the mean duration of their symptoms before implantation was 14.5 (3-40) ? years. Seventeen of the patients were female. All patients had symptoms of palpitation (lasting from two minutes up to 24 hours), ? and 12 patients had additional symptoms, including chest pain, dyspnoea, dizziness, and syncope.

Of the 22 patients, three had atrioventricular reentrant tachycardia associated with the 
Table 1 Exclusion criteria for antitachycardia pacing

1 Accessory pathway with short anterograde effective refractory period $(\leqslant 300 \mathrm{~ms})$.

2 Sustained atrial fibrillation induced by overdrive atrial pacing.

3 Inability to terminate arrhythmia reliably by overdrive pacing.

4 Symptomatic hypotension at onset of tachycardia. 5 Presence of other arrhythmias which might be treated inappropriately by pacing.

Wolff-Parkinson-White syndrome, six had atrioventricular reentrant tachycardia associated with a concealed accessory pathway, one had atrioventricular reentrant tachycardia associated with a Mahaim fibre, and 12 had atrioventricular nodal reentrant tachycardia. Most of these patients had no structural heart disease; one (patient 1) had valvar pulmonary stenosis (treated with valvotomy at the age of four) and one (patient 18) had an atrioventricular canal defect (closed surgically at the age of five), patent ductus arteriosus (ligated in infancy), and aortic coarctation.

\section{PREVIOUS TREATMENT}

All patients had previously been treated with one or more antiarrhythmic drugs (mean number of drugs, $5 \cdot 2(2 \cdot 8)$ ), either alone or in combination, and 13 patients had been treated with amiodarone. Also, six patients had had previous implantation of one or more different antitachycardia devices, which had not adequately controlled their symptoms. Patient 2 had previously had two different antitachycardia pacemakers (inserted in 1982 and 1984) and patient 19 had had four previous antitachycardia pacemakers implanted between 1977 and 1982 .

\section{ASSESSMENT BEFORE IMPLANTATION}

All patients underwent electrophysiological studies to find the mechanism of their tachycardias, the ease and reproducibility (or otherwise) of terminating their arrhythmias by atrial pacing, and any contraindications to antitachycardia pacing (table 1). Most patients underwent exercise testing, principally to find the maximum sinus rate on exertion.

As a final test of suitability for an antitachycardia device, all patients had a temporary atrial wire inserted through a subclavian vein and positioned in the right atrial appendage. This was connected to an antitachycardia pacemaker that had been adapted for external use and was used to start and stop tachycardia on repeated occasions, in the upright and recumbent positions, and during exertion. Only if the patient's symptoms could be adequately controlled under these circumstances was a permanent antitachycardia pacemaker inserted.

Pacemakers were implanted with standard techniques, usually involving cephalic vein cut down whenever possible. The lead was positioned in the right atrial appendage in all cases. The pacemaker was tested and the antitachycardia mode activated on the day after implantation, before the patient was discharged home. Patients subsequently attended the pacemaker clinic after one month, and thereafter at three to 12 monthly intervals.

\section{Results}

Tables 2 and 3 summarise the clinical data and pacing modes on the 22 patients. The mean (range) duration of follow up to date is $57 \cdot 3$ (19-76) months. There have been no deaths either related to the pacemaker or from other causes. Five patients required bradycardia support pacing for sinus node disease and long pauses after termination of tachycardia.

No patient has been lost to follow up. Table 3 summarises the pacing details of the patients who still have pacemakers. Five patients have their pacemakers programmed

Table 2 Clinical data

\begin{tabular}{|c|c|c|c|c|c|c|c|c|c|c|c|}
\hline $\begin{array}{l}\text { No } \\
\text { identity }\end{array}$ & Diagnosis & $\begin{array}{l}\text { Symptom } \\
\text { duration } \\
(y r)\end{array}$ & $\begin{array}{l}\text { No of } \\
\text { previous } \\
\text { drugs }\end{array}$ & $\begin{array}{l}\text { Previous } \\
\text { pacemakers }\end{array}$ & $\begin{array}{l}\text { Implant } \\
\text { date }\end{array}$ & $\begin{array}{l}\text { Age at } \\
\text { implant }\end{array}$ & $\begin{array}{l}\text { Removal } \\
\text { date }\end{array}$ & $\begin{array}{l}\text { Reason } \\
\text { for } \\
\text { removal }\end{array}$ & $\begin{array}{l}\text { Follow } \\
\text { up } \\
(y r)\end{array}$ & $\begin{array}{l}\text { Compli- } \\
\text { cations }\end{array}$ & $\begin{array}{l}\text { Current } \\
\text { drugs }\end{array}$ \\
\hline 1 & Conc AP & 22 & 7 & - & $5 / 85$ & 26 & - & - & $6 \cdot 4$ & - & - \\
\hline 2 & AVNRT & 5 & 8 & 2 & $6 / 85$ & 39 & - & - & $5 \cdot 4$ & $\begin{array}{l}\text { Thromb } \\
\text { AF }\end{array}$ & - \\
\hline 3 & AVNRT & 16 & 7 & - & $12 / 86$ & 44 & - & - & 4.9 & ?AF & BBl \\
\hline 4 & AVNRT & 15 & 5 & - & $2 / 86$ & 42 & - & - & $5 \cdot 2$ & - & - \\
\hline 5 & AVNRT & 5 & 8 & 1 & $11 / 85$ & 55 & - & - & $5 \cdot 3$ & - & - \\
\hline 6 & AVNRT & 4 & 4 & - & $5 / 85$ & 45 & - & - & $5 \cdot 9$ & - & - \\
\hline 7 & Conc AP & 17 & 4 & - & $7 / 85$ & 37 & - & - & $6 \cdot 0$ & $\begin{array}{l}\text { Sensing } \\
\text { failure }\end{array}$ & $\mathrm{BBl}$ \\
\hline 8 & WPW & 3 & 2 & - & $10 / 86$ & 53 & - & - & 4.9 & - & Ver \\
\hline 9 & Conc AP & 3 & 6 & - & $1 / 89$ & 45 & - & - & $2 \cdot 3$ & - & $\mathrm{BB} 1$ \\
\hline 10 & AVNRT & & & - & $2 / 85$ & 27 & - & - & $5 \cdot 2$ & - & Ver \\
\hline 11 & AVNRT & 7 & 4 & - & $8 / 85$ & 16 & - & - & $4 \cdot 1$ & - & - \\
\hline 12 & AVNRT & 7 & 4 & - & $2 / 87$ & 57 & - & - & $4 \cdot 2$ & - & $\bar{\pi}$ \\
\hline 13 & AVNRT & 40 & 8 & - & $7 / 85$ & 78 & - & - & $5 \cdot 4$ & - & Ver \\
\hline 14 & $\begin{array}{l}\text { Mahaim } \\
\text { fibre }\end{array}$ & 7 & 7 & - & $10 / 85$ & 17 & - & - & $5 \cdot 4$ & - & - \\
\hline 15 & WPW & 35 & 2 & 1 & $12 / 86$ & 38 & $7 / 88$ & Surg & $4 \cdot 2$ & Thromb & - \\
\hline 16 & Conc AP & 33 & 2 & - & $12 / 89$ & 73 & - & - & 1.6 & - & - \\
\hline 17 & WPW & - & - & - & $12 / 85$ & 32 & - & - & $5 \cdot 6$ & & - \\
\hline 18 & AVNRT & 10 & 3 & 1 & $6 / 85$ & 16 & $3 / 86$ & Inf & $6 \cdot 3$ & Inf & Dig Amio \\
\hline 19 & Conc AP & 14 & 7 & 4 & $8 / 85$ & 34 & $10 / 89$ & Surg & $4 \cdot 7$ & Thromb & - \\
\hline 20 & Conc AP & 35 & 6 & i & $8 / 85$ & 53 & $12 / 88$ & Surg & 5.9 & Dehisc & - \\
\hline 21 & AVNRT & 9 & 5 & - & $2 / 88$ & 43 & - & - & $3 \cdot 3$ & - & - \\
\hline 22 & AVNRT & 3 & 5 & - & $6 / 87$ & 26 & - & - & $2 \cdot 19$ & - & - \\
\hline
\end{tabular}

$\mathrm{AF}$, atrial fibrillation; Amio, amiodarone; AVNRT, atrioventricular nodal reentrant tachycardia; $\mathrm{BBl}$, beta blocker; Conc AP, concealed accessory pathway; Dehisc, wound dehiscence; Dig, digoxin; Inf, infection (see text); Surg, surgical ablation of accessory pathway; Thromb, venous thrombosis; Ver, verapamil; WPW, Wolff-Parkinson-White syndrome. 
Table 3 Pacing data

\begin{tabular}{|c|c|c|c|c|c|c|c|}
\hline $\begin{array}{l}\text { No } \\
\text { identity }\end{array}$ & $\begin{array}{l}\text { Pacing } \\
\text { mode }\end{array}$ & $\begin{array}{l}\text { Tachycardia } \\
\text { detection } \\
\text { mode }\end{array}$ & $\begin{array}{l}\text { Primary } \\
\text { response }\end{array}$ & $\begin{array}{l}\text { No of } \\
\text { pulses }\end{array}$ & $\begin{array}{l}\text { Secondary } \\
\text { response }\end{array}$ & $\begin{array}{l}\text { No of } \\
\text { pulses }\end{array}$ & $\begin{array}{l}\text { Frequencyl } \\
y r\end{array}$ \\
\hline 1 & OAO-T & 7 & $\mathbf{S}$ & 6 & $S$ & 10 & 46 \\
\hline 2 & OAO-T & 3 & 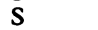 & 6 & S & 8 & 310 \\
\hline 3 & OAO-T & 3 & S & 6 & A & 8 & 42 \\
\hline 4 & OAO-T & 1 & $S$ & 6 & s & 10 & 28 \\
\hline 5 & AAI-T & 4 & 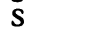 & 7 & s & 10 & 14 \\
\hline 6 & AAI-T & 3 & S & 6 & Off & - & 1530 \\
\hline 7 & OAO-T & 1 & A & 8 & A & 10 & 117 \\
\hline 8 & OAO-T & 2 & $S$ & 6 & A & 8 & 510 \\
\hline 9 & OAO-T & 2 & $S$ & 6 & S & 8 & 510 \\
\hline 10 & OAO-T & 4 & $S$ & 6 & S & 3 & - \\
\hline 11 & OAO-T & 5 & $\mathrm{~S}$ & 8 & A & 7 & 310 \\
\hline 12 & OAO-T & 5 & S & 6 & Off & - & 206 \\
\hline 13 & AAI-T & 7 & A & 10 & $S$ & 20 & 96 \\
\hline 14 & OAO-T & 2 & $\mathrm{~S}$ & 4 & S & 3 & - \\
\hline 16 & AAI-T & 1 & $\mathrm{~S}$ & 6 & $\mathrm{~S}$ & 2 & 510 \\
\hline 17 & OAO-T & 7 & $S$ & 10 & S & 6 & 24 \\
\hline 21 & OAO-T & 3 & $S$ & 10 & S & 6 & 6 \\
\hline 22 & AAI-T & 6 & $\mathrm{~s}$ & 6 & Off & - & 0 \\
\hline
\end{tabular}

A, autodecremental (accelerating rate within each burst); S, scanning (constant rate within each pacing burst). Tachycardia detection algorithms used: 1 , High rate only; 2 , High rate + sudden onset; 3 , High rate + (sudden onset or sustained high rate) 4 , High rate + rate stability; 5 , High rate + (rate stability or sustained high rate); 6 , High rate + sudden onset + rate stability; 7 , High rate + (sudden onset + rate stability)) or sustained high rate).

to provide bradycardia support in addition to tachycardia termination of these patients, two are being treated with $\beta$ blocking drugs. The tachycardia detection algorithms used are as shown; the high rate criterion alone has been sufficient for three patients, whereas the others have more complex algorithms.

\section{COMPLICATIONS}

Pacemakers were removed from five patients. Patient 11 developed signs of acute infection within days of implantation and had the system removed and a new system implanted on the other side 21 days later. Patient 18 (who had complex congenital heart disease) had persistent pain at the generator site and an intermittent pyrexia; this was attributed to low grade chronic infection and the unit was removed nine months after implantation. The pyrexia resolved a few weeks after removal of the pacemaker. Patients 15, 19, and 20 had surgical ablation of accessory pathways, 19, 50 , and 40 months after implantation.

Three patients (patients 2, 15, and 19) had problems with venous thrombosis at the site of the pacing lead, and two of these three patents eventually had the pacemaker removed and surgical ablation of accessory pathways. It is notable that all three of these patients had had previous antitachycardia pacemakers with ventricular leads, and in each case at least one right ventricular lead remained in situ. In fact, patient 2 had had two previous pacemakers, and patient 19 had had four pacemakers in the past.

Patient 20 developed skin erosion over the generator 17 months after implantation. The generator was repositioned and continued to function for a further 23 months, at which time it was removed when the patient underwent surgical ablation of her accessory pathway. Patient 3 had one episode of irregular palpitations that might have been due to atrial fibrillation, but this arrhythmia has never been documented. Patient 7 has had symptoms of tachycardia that have not been registered by the pacemaker, possibly because of intermittent sensing failure. Patients 9 and 12 have both had tachycardias that have gone undetected because their rate has been slower than the programmed tachycardia detection rate; in each case, these have responded well to reprogramming the high rate criterion to a lower figure.

\section{TERMINATION OF TACHYCARDIA}

Table 3 shows some of the programmed characteristics of 18 patients being followed up. In all but two cases, the primary antitachycardia response is a burst of four to $\overrightarrow{\overrightarrow{0}}$ eight beats, at a cycle length of $75 \%-90 \%$ of $\exists$ the tachycardia cycle; if the tachycardia persists, the burst is repeated at progressively shorter cycles (decremental scanning). In patients 7 and 13, the primary antitachycardia response was a burst of eight or 10 beats during which the pacing cycle length gradually shortened (autodecremental burst pacing).

In all but three patients, a secondary mode 옹 was programmed to come into effect if the $D$ primary mode was unsuccessful. In 11 patients, this consisted of a train of stimuli $\tilde{\sigma}$ slightly longer or faster than the primary $N$ response, with decremental scanning as $\mathrm{N}$ before, in four patients the secondary mode $\stackrel{\omega}{\sigma}$ consisted of autodecremental pacing. The frequency column in table 3 gives an indication of how often each patient's pacemaker $\stackrel{9}{?}$ had been activated, based on the data 0 obtained at interrogation of the device at the last attendance at the clinic. As the device's $\cong$ counters have only 256 slots (numbered from $\mathbb{Q}$ 0 to 255), a figure of 255 will continue to register even if the patient has had 256 or 8 more episodes of tachycardia since the last occasion on which the counters were cleared. For this reason, many of the figures in this column may be underestimates of the true frequency of tachycardia (for example, the figure of 510 for patients 8 and 9 represents at least 255 episodes of tachycardia in a six month period). 


\section{CONCOMITANT DRUG TREATMENT}

Four of the 18 patients in table 3 are receiving $\beta$ blockers; all four had been prescribed $\beta$ blocking drugs in the past but had been inadequately controlled on these drugs. Patient 8 is being treated with verapamil for hypertension (previously ineffective for tachycardia control) and thyroxine for amiodarone induced hypothyroidism. Patients 10 and 13 are also taking verapamil, to reduce the frequency of attacks of tachycardia. The other 11 patients do not require any drug treatment.

Patient 19 started taking atenolol shortly after implantation of his pacemaker in 1985, and continued to take this drug until his operation in 1989. Patient 18, who had her pacemaker removed in 1986 , is now being treated with digoxin and amiodarone.

No patient has required emergency hospital admission or intravenous medication to terminate tachycardia since implantation of the pacemaker.

\section{Discussion}

This study describes the follow up of 22 patients who had antitachycardia pacemakers implanted during the years 1985 to 1989 . The fact that 17 of the units were implanted during the first two years reflects partly our initial enthusiasm for a new type of antitachycardia pacemaker that became available in early 1985, and partly the fact that we (and other centres) have been more inclined to offer patients curative techniques, such as surgery or catheter ablation, in the past few years.

There have been few studies of long-term follow up of multiprogrammable antitachycardia pacemakers of this type. McComb et al recently reported on a series of 22 patients in whom Intertach $262-12$ or 262-16 pacemakers had been implanted in a single centre between 1987 and $1990 .^{5}$ Their experience is similar to ours, although their follow up period (mean 14.8 months) is considerably shorter (mean $57 \cdot 3$ months). Four of their patients are receiving $\beta$ blockers, and one is taking antiarrhythmic drugs. Fromer et al have recently reported their data on 16 patients in three centres followed up for a mean period of 30.9 months. ${ }^{67}$ Two of their patients have undergone surgical cure of their arrhythmias. $\mathrm{Li}$ et al compared the cost of follow up of an Intertach 262-12 antitachycardia pacemaker with that of pharmacological treatment, and also assessed their patients' quality of life before and after implantation. ${ }^{8}$ They concluded that antitachycardia pacing was both cost effective and beneficial in terms of quality of life in their 17 patients, although they did not include the costs of the initial pacemaker implantation in their assessment.

EXPLANATION

Four patients with supraventricular arrhythmias had their pacemakers removed, at intervals of nine to 50 months after implantation.
It is notable that all four of these patients had had at least one previous antitachycardia pacemaker inserted, all four had pacemaker related problems (venous thrombosis in two, wound dehiscence in one, and possible chronic infection in one), and all four had at least one ventricular lead in situ from the previous pacemaker(s). Also of note is the fact that three of these four patients had accessory pathways, and the pacemaker was removed at the time of surgical ablation of the accessory pathway. In part this represents our willingness to replace the palliative treatment of antitachycardia pacing with the curative treatment of surgery in these patients with complications.

\section{SENSING ALGORITHMS AND PACING}

\section{MODALITIES}

The choice of a suitable algorithm for sensing a particular patient's tachycardia depends on the rate of the tachycardia or tachycardias to be treated, the maximum rate of sinus tachycardia, and whether there is any overlap between them, the circumstances that induce the tachycardia (for example exercise, when the sinus rate is rapid), and whether the patient is prone to other arrhythmias that the pacemaker should not attempt to overdrive (for example atrial fibrillation). With the pacemaker used in this series, a combination of four detection features (high rate, sudden onset, rate stability, sustained high rate) can be programmed independently. There are no published studies that have attempted to find the best tachycardia detection algorithm, mainly because the suitability of a particular algorithm will vary between patients, and may also vary within one patient depending on factors such as concomitant drug treatment, changes in arrhythmia substrate or autonomic tone, and development of new arrhythmias. Choice of detection algorithm therefore depends on the characteristics of the individual patient, and can perhaps be helped by exercise testing (to determine the maximum sinus rate on exercise) and spontaneous recordings of the onset of the clinical arrhythmia. Although it has been suggested that the rate stability variable may be helpful in discriminating between a regular supraventricular tachycardia and atrial fibrillation, this hypothesis was not tested in our patients, and it seems likely that the rate of the sensed atrial electrogram during atrial fibrillation would be more rapid than the maximum programmed pacing rate of the pacemaker. In our series most patients had a detection algorithm that required two or more criteria to be satisfied (one of them of necessity being high rate) before the pacemaker would attempt to terminate the tachycardia. The high rate criterion alone was used in three patients. We did not find a particular algorithm to be better than the others-on the contrary, the algorithms chosen were tailored to each individual patient. This obviously added to the time spent on initial assessment and follow up of the patients. 
Similarly, the program used for antitachycardia pacing in each patient must be decided on an individual basis, and should ideally be based on the success of a number of trials to end tachycardia, not only in the electrophysiology laboratory, but also as the patient is sitting, standing, and exercising. We believe that our protocol before implantation provides the optimum basis for evaluating each patient and for finding which sensing and pacing modes are most appropriate for each patient. As antitachycardia pacing is a palliative rather than a curative form of treatment, the patients continue to experience paroxysmal tachycardia, albeit of short duration, before the pacemaker can terminate it. Hypotension at the onset of tachycardia, which can be profound when the patient is standing, may produce severe symptoms. The testing before implantation was undertaken to provide reassurance that residual symptoms associated with the onset of tachycardia under different physiological conditions would be acceptable.

There have been several trials of different modes of antitachycardia pacing. Holt et al used the Siemens-Elema Tachylog to assess the relative efficacy of burst pacing, self searching, and adaptive scanning techniques. ${ }^{9}$ They found that burst pacing was the most effective method, although it was more likely to induce unwanted arrhythmias such as atrial fibrillation. Nathan et al compared autodecremental with fixed rate atrial pacing in 20 patients with supraventricular tachycardia, and found that a five second burst of autodecremental pacing was successful in every case, and less likely to induce atrial flutter or fibrillation than fixed rate bursts. ${ }^{10}$ Charos et al have shown that autodecremental pacing is more likely to be effective than scanning burst pacing, with a constant cycle length within the burst and a programmed change in burst cycle length at subsequent attempts. ${ }^{11}$ den Dulk et al have described an adaptive pacing mode with an automatically increasing number of stimuli, which they describe as a universal pacing mode. ${ }^{12}$ This seemed to be more successful than standard scanning mode. In our series, we have used autodecremental pacing in a relatively small number of patients (and usually as a secondary mode). The reason for this is that all our patients had tachycardias that were reliably ended by burst pacing without varying the rate within the burst. The universal mode cannot be programmed in the Intertach pacemaker.

Although several of the patients in our series had their tachycardia detection or termination algorithms reprogrammed at certain times during follow up, it has not been possible to obtain complete data on the number of reprogrammings undertaken in every case.

We present the results of follow up of 22 patients in whom an Intertach antitachycardia pacemaker was implanted between 1985 and 1989. We stress the importance of patient selection with regard to suitability and efficacy of such a device. In recent years there has been an increasing trend towards the use of curative procedures such as catheter ablation and surgery, and the indications for antitachycardia pacemaker implantation are diminishing now that most patients with atrioventricular reentrant tachycardia or atrioventricular nodal reentrant tachycardia can be cured by these techniques. In future the need for implantation of an antitachycardia pacemaker for supraventricular arrhythmias may be limited to those in whom catheter ablation is unsuccessful and surgery is undesirable (either because of patient preference or in high risk cases), and to those patients who will require pacing for concomitant sinus node disease. Although the results of curative procedures for ventricular and supraventricular arrhythmias are continuing to improve, permanent antitachycardia pacing remains a useful and appropriate palliative treatment with an acceptable longterm success rate for carefully selected patients.

We thank Drs AJF Page, AP Rae, JD Skehan, S Webb, RG Wilcox, and $\mathrm{Mr} \mathrm{L}$ Lewis for providing information on patients who are currently attending their clinics, and our own technical staff for their continued assistance in following up ou patients.

1 de Belder MA, Malik M, Ward DE, Camm AJ. Pacing modalities for tachycardia termination. PACE 1990;13: 231-48.

2 Barold SS, Ryan GF, Goldstein S. The first implanted tachycardia-terminating pacemaker. $P A C E$ 1989;12: $870-4$

3 Spurrell RAJ, Nathan AW, Bexton RS, Hellestrand KI, Nappholz T, Camm AJ. Implantable autonomic scanning pacemaker for termination of supraventricular tachycardia. Am $\mathcal{F}$ Cardiol 1982;49:753-60.

4 Griffin JC, Sweeney M. The management of paroxysmal tachycardias using the Cybertach-60. PACE 1984; 7:1291-5.

5 McComb JM, Jameson S, Bexton RS. Atrial antitachycardia pacing in patients with supraventricular tachycardia clinical experience with the Intertach pacemaker. $P A C E$ 1990;13:1948-54.

6 Fromer M, Gloor H, Kus T, Shenasa M. Clinical experience with a new software-based antitachycardia pacemaker for recurrent supraventricular and ventricular tachycardias. PACE 1990;13:890-9.

7 Fromer M, Gloor H, Kus T, Kappenberger L, Shenasa M. Clinical experience with the Intertach $262-12$ pulse generator in patients with recurrent supraventricular generator in patients with recurrent supraventric

$8 \mathrm{Li} \mathrm{C}$, Shandling AH, Nolasco M, Thomas LA, Messenger JC, Warren J. Atrial automatic tachycardia-reversion pacemakers: their economic viability and impact on pacemakers: their economic viability

9 Holt P, Crick JCP, Sowton E. Antitachycardia pacing: a comparison of burst overdrive, self-searching and adaptive table scanning programs. PACE 1986;9:490-7.

10 Nathan A, Hellestrand K, Ward D, Spurrell R, Camm J. Rate-related accelerating (autodecremental) atrial pacing for reversion of paroxysmal supraventricular tachycardia. $¥$ Electrocardiol 1982;15:77-84.

11 Charos GS, Haffajee CI, Gold RL, Bishop RL, Berkovitz BV, Alpert JS. A theoretically and practically more Bf, Alpert J. A for interruption of ventricular tachycardia: Self-adapting autodecremental overdrive pacing. Carculation 1986;73:309-15.

12 den Dulk $\mathrm{K}$, Kersschot IE, Brugada $\mathrm{P}$, Wellens HJJ. Is there a universal antitachycardia pacing mode? $A m \mathcal{F}$ Cardiol 1986;57:950-5. 